\title{
Profile of Dr. Shougong Zhang
}

Dr. Shougong Zhang received his bachelor's degree in agriculture (forestry) from Anhui Agricultural College, Hefei, China, in January 1982, and obtained his Ph.D. degree in agriculture (forest management) from Beijing Forestry University, Beijing, China, in 1990. From 1982 to 1986, he taught silviculture and forest mensuration in Anhui Agricultural University. From 1990 to 1997, he worked in the Research Institute of Forestry of the Chinese Academy of Forestry (CAF), Beijing, China, and served as the Deputy Director and then the Director of the Institute. He served as the Vice President of CAF in 1997, then the Executive Vice President in 2002, and has been the President since 2007.

Dr. Zhang is now the Vice Director of the Committee of Resources and Environmental Protection of the 13th National People's Congress. He used to serve as Member of the Executive Board of the International Union of Forest Research Organizations, the principal scientist of the National Basic Research Program (973 Program), and the member of the expert panel of agricultural sector for the National Hightech R\&D Program (863 Program). He holds concurrent posts as the Vice President of the Chinese Society of Forestry and the President of its Sub-Society of Silviculture.

Dr. Zhang is a professor with specialties of silviculture and forest management. He has been doing research on quality improvement and high efficiency cultivation technology of larch, catalpa, spruce, etc. for quite a long time. He has made several creative achievements in the research fields of ecological tree breeding, improved variety industrialization engineering technology and oriented cultivation model of commercial forest for larch species, and has bred 24 improved materials of larch species which have been extended into mass application in the practice. He created an innovative model structure, raised a new and integrated method of growth simulation and dynamic economic evaluation model, and solved the difficult problem of disconnection from each other between growth efficiency of silvicultural measures and income efficiency of cultivation,

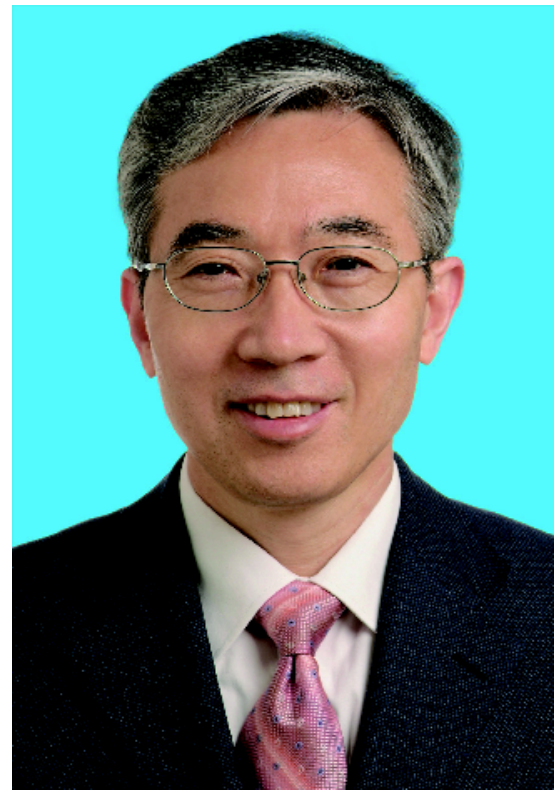

which provides an advanced and high-efficiency solution for comprehensive cost-effectiveness analysis of several silvicultural measures and the whole process optimization of management plan. He made a breakthrough in solving the technical bottleneck of synchronization scale of cotyledon embryo, and created a synchronization propagation technology system for somatic embryos of larch species. He won three second-class prizes of the National Science and Technology Progress Award, and two first-class prizes of ministerial- and provincial-level Science and Technology Progress Award. He obtained 14 invention patents, published 263 academic articles, and led the development of one national standard and eight forestry sector standards. He has made significant contribution to the theory and technical development of planted forest cultivation and sustainable forest management.

Dr. Zhang was elected as Member of the Chinese Academy of Engineering in 2017. 